\title{
Advanced Malignant Neoplasm
}

National Cancer Institute

\section{Source}

National Cancer Institute. Advanced Malignant Neoplasm. NCI Thesaurus. Code C9270.

A malignant neoplasm that has spread extensively to other anatomic sites or is no longer responding to treatment. 